S. Yabusaki

June 1981

June 1981

Pacific Northwest Laboratory
Operated for the U.S. Departm
by Battelle Memorial Institute

\title{
The Migration of Strontium-90
From a Strontium-90 Fluoride \\ The Migration of Strontium-90
From a Strontium-90 Fluoride \\ Deep Ocean Source
}

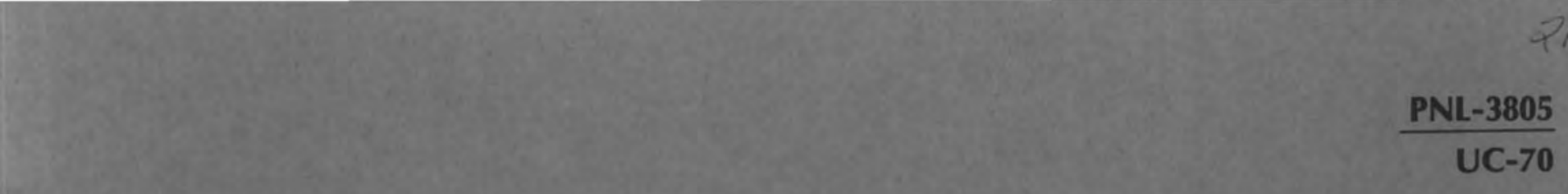

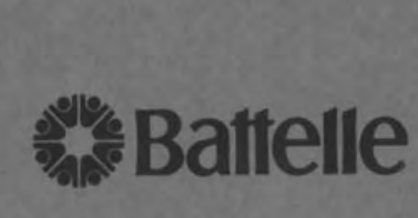

,

$=$

(x)

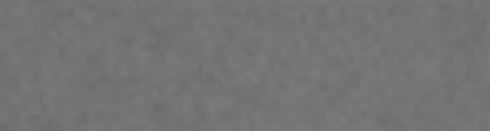




\title{
NOTICE
}

This report was prepared as an account of work sponsored by the United States Government. Neither the United States nor the Department of Energy, nor any of their employees, nor any of their contractors, subcontractors, or their employees. makes any warranty, express or implied, or assumes any legal liability or responsibility for the accuracy, completeness or usefulness of any information, apparatus, product or process disclosed, or represents that its use would not infringe privately owned rights.

The views, opinions and conclusions contained in this report are those of the contractor and do not necessarily represent those of the United States Government or the United States Department of Energy.

\author{
PACIFIC NORTHWEST LABORATORY \\ operated by \\ BATTELLE \\ for the \\ UNITED STATES DEPARTMENT OF ENERGY \\ Under Contract DE-AC06-76RLO 1830
}
Printed in the United States of America Available from
National Technical Information Service United States Department of Commerce 5285 Port Royal Road
Springfield, Virginia 22151

Price: Printed Copy $\$$ $\because$ Microfiche $\$ 3.00$
-Pages Nirs Selling Price

051-075 \$5.25

$076.100 \quad \$ 6.00$

$101.125 \quad \$ 6.50$

126-150 \$7.25

$151-175 \quad \$ 8.00$

176-200 $\$ 9.00$

$201-225 \quad \$ 9.25$

226-250 \$9.50

251-275 $\$ 10.75$

$276-300 \quad \$ 11.00$ 
THE MIGRATION OF STRONTIUM-90

FROM A STRONTIUM-90 FLUORIDE

DEEP OCEAN SOURCE

\section{S. Yabusaki}

June 1981

Prepared for the U.S. Department of Energy Under Contract DE-ACO6-76RLO 1830

Pacific Northwest Laboratory

Richland, Washington 99352 
.

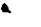




\section{ABSTRACT}

A hypothetical rupture of a heat source capsule on the ocean floor is analyzed for strontium-90 migration and attenuation. The evolution of the three-dimensional contaminant plume is simulated by a modified version of the Okubo-Pritchard radially symmetrical, diffusion velocity dispersion model. Results from this study indicate that released solutes are confined vertically to a layer near the level of introduction. Along the plume centerline, however, water quality is affected for considerable distances downstream from the source, with the maximum effect occurring after one year. 

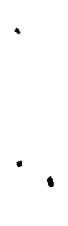

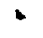




\section{CONTENTS}

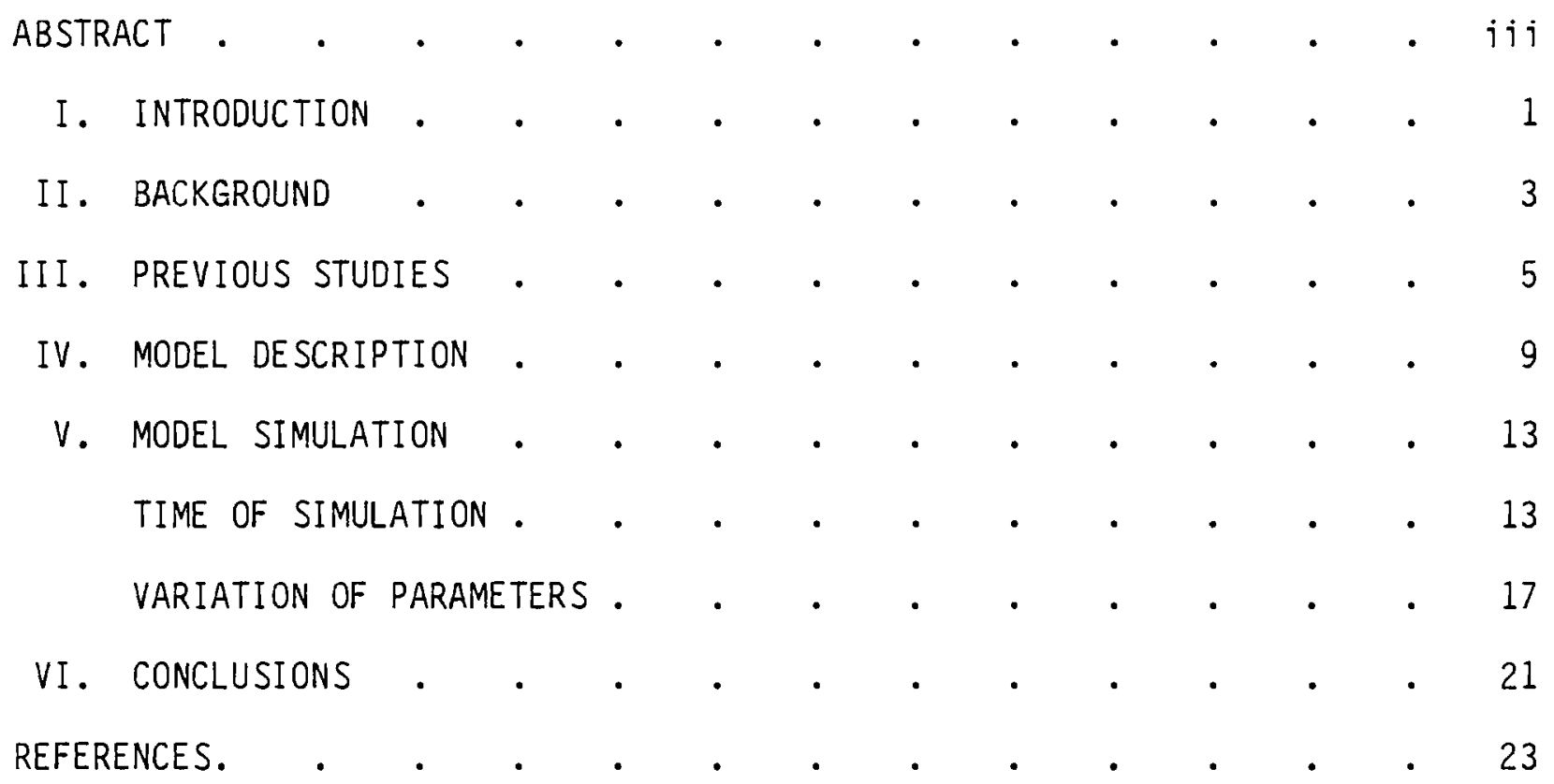




\section{FIGURES}

1 Horizontal Profile of Concentrations for 10 Days of

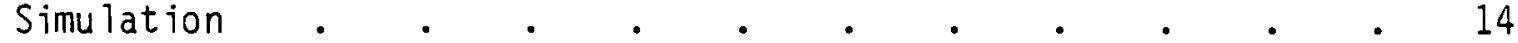

2 Horizontal Profile of Concentrations for 2 Years of

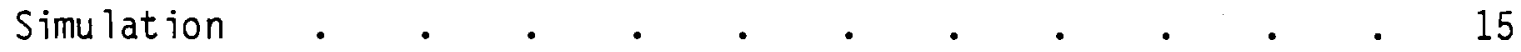

3 Concentration Versus Maximum Distance From Source: 10 Day, 1 Year, 2 Year, and 5 Year Time Periods . . . . 16

4 Concentration Versus Maximum Distance From Source: Increased Source (10Q), Extreme Conditions, and 1 Year Baseline . . . 19

5 Vertical Profile of Concentrations for 2 Years of

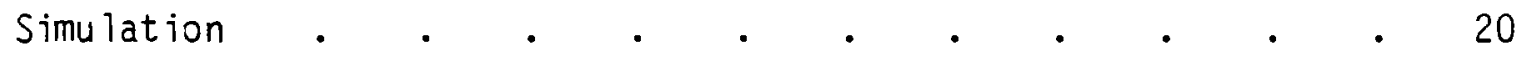




\section{INTRODUCTION}

This report presents the analys is of a continuous fixed point release of radioactive material in the deep ocean. Specifically, a hypothetical ocean floor deposition of strontium-90 fluoride by-product is evaluated for radionuciide transport and dispersion. The release of ${ }^{90} \mathrm{SrF}_{2}$ is assumed to occur on the ocean bottom by the rupture of a heat source capsule which contains $2.8 \mathrm{~kg}$ of $\mathrm{SrF}_{2}$. The objective of this study is the generation of concentration profiles for the diffused and advected strontium-90 solute. The simulation of the contaminant plume is achieved by applying a modified version of the OkuboPritchard "diffusion velocity" model (Okubo 1962). These modifications extend the capability of the model to include three-dimensional mixing and local velocity effects.

A general review of the pertinent physical processes involved in deep ocean dispersion is found in Section 2. Appiicable mode is of previous oceanic research are discussed in Section 3, while Section 4 contains a detailed description of the mathematical model selected for use in this study. The results of the various simulations are presented and interpreted in Section 5. Concluding remarks and recommendations are included in Section 6 .

This study was carried out as part of the Strontium Heat Source Development Program, which is sponsored by the Space and Terrestrial Systems Division of the Department of Energy. 
-

$\bullet$ 


\section{BACKGROUND}

Ocean waters can be categorized into three layers, each of which displays depth-dependent behavior. The well-mixed upper layer is subject to the influence of wind and seasonal change. It is in this layer that predominant currents and highly turbulent motions are found. Separating the upper layer from the deep layer is the thermocline, a very stable layer appearing at an average depth of 200 meters. Lying be low the thermocline is the deep layer, upon which the attention of this study is focused.

Over three-fourths of the total area of water on the earth lies over the oceanic abyss with depths greater than 3000 meters. In contrast to the surface layer, these deep waters do not exhibit strong mixing. Wind effects are negligible; therefore, currents found in this layer are attributed largely to density differences. Near the ocean bottom, vertical motion is of the order $10^{-5} \mathrm{~cm} / \mathrm{sec}$, a very sma 11 value compared with the magnitude of the horizontal currents, which are of the order $1 \mathrm{~cm} / \mathrm{sec}$. Consequent ly, the mean residence time of water found in the deep ocean is, roughly, 1000 years. Despite this apparent insignificance, properties in the vertical must be taken into account, not so much for their absolute magnitude, but because vertical gradients are usually much larger than their horizontal counterparts.

The complete spectrum of water movement can be described by the equation of motion. However, the detailed prediction of flow phenomena requires the precise quantification of countless environmental factors which are beyond the control of the modeler. Thus, the wide range of irregular motion which exists in the ocean can realistically be treated only in a statistical fashion.

From a practical standpoint, these currents which cannot be resolved in a straightforward manner, due to the randomness of their appearance, are labeled turbulence. Ocean turbuience is distinctively anisotropic except for sca ies of motion which are very small. This anisotropy is explained in part by the ocean's extensive horizontal dimension compared with the relatively shallow depth. Additionally, the existence of sharply stratified layers of water further inhibit the occurrence of large vertical eddies. 
The most important characteristic of turbulence is the role it plays in the diffusion process. In conjunction with the process of advection, diffusion provides the mechanism responsible for the dispersion of a contaminant about a release point. Advection is usually defined as transport caused by the large-scale movement of water, whereas diffusion is the physical exchange of substance without regard for the overa 11 propagation of the contaminant. Diffusion can be further decomposed into two fundamental types: molecular diffusion and turbulent diffusion. In the ocean, however, mixing produced by molecular exchange is negligible when compared with mixing induced by turbulent diffusion.

Consider the evolution of a contaminant plume in the ocean. During the initial moments after release, the local current as well as large eddies will move the plume as a whole without any internal relative motion. Small scale turbulent motions, i.e., motions whose length scale is considerably less than the dimensions of the plume, will diffuse the plume along and about the centerline of the local current. Eddies on the order of the size of the plume will create spatial variations in velocity which deform the plume shape and enhance mixing. As the size of the contaminant plume increases with time, larger length scales become available to the dispersion process. More energy is contained in these large scale eddies than in the smaller eddies; consequently, mixing accelerates with increasing plume size. For this reason, diffusion described by a constant diffusivity, i.e., Fickian diffusion, is inappropriate for oceanic mixing. 


\section{PREVIOUS STUDIES}

Presently, there is no analytical method which fundamentally describes turbulent fluid flow. This is the closure problem of fluid mechanics which effectively precludes an exact solution. Although often criticized, the use of an eddy viscosity term provides a simple means to close the equation set and yield results which are reasonable in light of experimental verification. With this approximation for the turbulence correlation, the advectiondiffusion equation, with radioactive decay included, becomes:

$$
\frac{\partial S}{\partial t}+u_{j} \frac{\partial S}{\partial x_{j}}=\frac{\partial}{\partial x_{j}}\left(K_{i j} \frac{\partial S}{\partial x_{i}}\right)-\lambda S
$$

where

$$
\begin{aligned}
& u_{j} \text { and } k_{i j} \text { are functions of time and position } \\
& k_{i j} \text { is a second order tensor which can be simplified to } \\
& \quad k_{i j} \geq 0 \text { for } i=j \\
& \quad k_{i j}=0 \text { otherwise } \\
& S=\text { concentration of contaminant } \\
& u=\text { velocity } \\
& k=\text { eddy diffusivity } \\
& \lambda=\text { radioactive decay constant } \\
& x=\text { coordinate direction } \\
& t=\text { time } \\
& i, j=\text { tensor indices }
\end{aligned}
$$

For an instantaneous release, various solution techniques may be employed to solve this partial differential equation. Continuous release models, however, are not fundamental, as they rely completely on a prior knowledge of an instantaneous source solution. Mathematically, an approximate contaminant plume model can be achieved by integrating the instantaneous solution over time 
with a continuous contaminant release rate. Physically, this is tantamount to the "superposing of an inf inite number of overlapping instantaneous patches, each being released from a fixed origin, and each being translated (by the velocity field)." (Okubo and Pritchard 1969)

Of the various methods of modeling a contaminant dispersion event, two basic approaches, shear diffusion and radial symmetry, are noteworthy (Okubo and Pritchard 1969). Shear diffusion solutions are founded on the principle that mixing occurs as a result of velocity shear and small scale turbulent diffusion. This method is formulated to detail horizontal dispersion produced by the interaction of vertical shear in the mean flow and vertical diffusion. Okubo and Pritchard (1969) have shown that the shear diffusion solution is more physically explicit than the radially symmetrical solution, i.e., the radially symmetrical solution is actually a particular instance of the shear diffusion solution. However, there are drawbacks to the method. Although plume deformation is more realistic in the shear diffusion solution, data requirements for the velocity flow field are highly location-specific. Thus, the modeling of a contaminant plume in a nondescript ocean environment is not feasible. A larger concern is the difficulty in handiing the presence of boundaries near the release point which is an important consideration in oceans where stratification exists and especially where an ocean bottom release is studied.

On the other hand, the radially symmetrical solution assumes isotropic horizontal turbulence to be the primary influence in dispersing contaminants. At a given depth, concentration distributions produced by this method are symmetrical about the axis of the local current. Two types of radially symmetrical solutions are presently available: 1) diffusion velocity and 2) energy dissipation. The diffusion velocity approach is based on the theory that the rate of dispersion depends only on a characteristic velocity which is related directly to the turbulence intensity.

The energy dissipation method assumes that the eddies involved in the horizontal dispersion of a contaminant be in the inertial subrange of the turbulent energy spectrum. This range of eddy sizes is not directly affected by the prevailing energy transfer and dissipation mechanisms. Thus, if the 
energy of these eddies remains constant, diffusive behavior can be related directly to the rate of energy dissipation. The limitation to the inertial subrange, however, will create difficulties where local additions of energy excite eddies into different energy spectra.

In the radially symmetrical solution, the image source/sink method is easily incorporated to manage the presence of boundaries in the mixing zone. Data requirements are modest and the solution is amenable to the nonspecific ocean bottom location of this study. Certainly a detailed description of the shape variation in the plume will not be possible, although the mean horizontal spread of radioactivity which is generated is quite sufficient for our objectives. Of the two radially symmetrical solutions presented, the diffusion velocity approach appears to have a larger range of applicability due to the limitation of the turbulent energy transfer solutions to the inertial subrange. of the various diffusion velocity models available, this study uses the OkuboPritchard (Okubo 1962) model to simulate the evolution of the contaminant plume. 


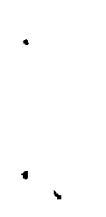

$\bullet$ 


\section{MODEL DESCRIPTION}

The Okubo-Pritchard (Okubo 1962) solution is a two-dimensional instantaneous source solution. As modified by Toblin (1972), this model is capable of simulating the evolution of a three-dimensional contaminant plume from a continuous radioactive source under the influence of a local current. The equation of interest is:

$$
\begin{aligned}
S(x, y, z, t)= & \int_{0}^{t} \frac{Q\left(t-t^{\prime}\right)}{\pi^{3 / 2} \omega^{2} t^{5 / 2} K_{z}^{1 / 2}} \exp \left[-\frac{\left(x-u t^{\prime}\right)^{2}+y^{2}}{\omega^{2} t^{\prime 2}}-\lambda t^{\prime}\right] \\
& {\left[\sum_{i=1}^{\infty} \exp \left\{-\frac{\left(z+N_{i} z^{\prime}\right)^{2}}{4 K_{z} t^{\prime}}\right\}\right] d t^{\prime} }
\end{aligned}
$$

where

$$
\begin{aligned}
S & =\text { contaminant concentration, } \mathrm{C} i / \mathrm{cm}^{3} \\
Q & =\text { source term, } \mathrm{C} i / \mathrm{s} \\
\omega & =\text { diffusion velocity, } \mathrm{cm} / \mathrm{s} \\
K_{z} & =\text { vertical eddy diffusivity, } \mathrm{cm}^{2} / \mathrm{s} \\
u & =\text { local current velocity } \mathrm{cm} / \mathrm{s} \\
z_{b} & =\text { layer thickness, } \mathrm{cm} \\
N_{i} & =i-1 \text { if } i \text { is odd, }-i \text { if } i \text { is even } \\
x & =\text { coordinate direction (along axis of current) } \\
y & =\text { horizontal coordinate direction } \\
z & =\text { vertical coordinate direction } \\
t & =\text { simulation time, sec } \\
t^{\prime} & =\text { time, sec }
\end{aligned}
$$

Assumptions upon which the model is based are as follows:

1. ambient velocity is constant and lies along a straight line

2. vertical diffusion is approximated by a constant diffusivity 
3. vertical velocity is negligible compared with vertical diffusion

4. uptake of activity from suspended or dissolved radionuclides on to bottom sediments is negligible.

Data requirements for the mathematical model are $u, w, z_{b}, k_{z}, t$, and Q. Except for $Q$, representative values of these parameters can be found in the literature (Pritchard 1960) for various ocean layers. This study uses Pritchard's deep ocean specifications:

$$
\begin{aligned}
u & =2.0 \mathrm{~cm} / \mathrm{s} \\
w & =0.2 \mathrm{~cm} / \mathrm{s} \\
z_{b} & =2000 \mathrm{~m} \\
k_{z} & =1.0 \mathrm{~cm}^{2} / \mathrm{s} \\
t & =1 \text { year }
\end{aligned}
$$

The scenario for this report is that $2800 \mathrm{~g}$ of solid strontium-90 fluoride has been deposited intact on the floor of the deep ocean. The dissolving mass produces a dynamically neutral solute which contains the strontium-90 radionuclide. In the ocean, it is unlikely that the solubility concentration will be exceeded; nevertheless, concentrations near the release point must be monitored for such an occurrence, as this will require that modifications be performed on the source function.

The most important input into the model is the radioactive source function, Q. Data from chemical studies (Fullam 1976, 1977) of strontium-90 fluoride provided the information necessary for the development of the source function. Pertinent information from the chemical analyses is as follows:

$$
\begin{aligned}
& \text { initial mass of strontium-90 fluoride }=2800 \mathrm{~g} \\
& \text { chemical purity }=95 \% \\
& \% \text { strontium }=70.1 \% \\
& \% \text { strontium-90 }=50 \% \\
& \text { dissociation rate }(D)=8.23 \times 10^{-8} \frac{\mathrm{g} \text { Sr dissolved }}{\mathrm{g} \text { Sr initial-sec }} \\
& \text { activity }(A)=139 \mathrm{Ci} / \mathrm{g} \\
& \text { solubility concentration } \cong 0.1 \mathrm{~g} / \mathrm{l} \\
& \text { background concentration }=0.0081 \mathrm{~g} / \mathrm{l} \\
& \text { decay constant }=7.83 \times 10^{-10} \mathrm{sec}^{-1}
\end{aligned}
$$


The source function, $Q$, is the product of the undissolved ${ }^{90} \mathrm{Sr}$ mass, $S_{0}$, the dissociation rate, $D$, and the activity, $A$. Since the undissolved mass is always changing, a decay relation is used to more accurately account for the dissociating solid:

$$
Q=\left(S_{0} e^{-D t}\right) D A
$$

where

$$
\begin{aligned}
S_{0} & =\text { initial strontium-90 mass, } \mathrm{g} \\
& =(2800 \mathrm{~g})(0.95)(0.701)(0.50) \\
& =932 \mathrm{~g}
\end{aligned}
$$

Thus, the initial strength of the source is:

$$
\begin{aligned}
Q & =(932 \mathrm{~g})\left(8.23 \times 10^{-8} \frac{\mathrm{g} S r \text { dissolved }}{\mathrm{g} S \mathrm{initial-sec}}\right)\left(139 \frac{\mathrm{C} i}{\mathrm{~g}}\right) \\
& =0.0107 \frac{\mathrm{C} i}{\mathrm{Sec}}
\end{aligned}
$$




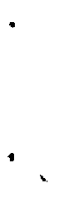

' 
V. MODEL SIMULATION

The mathematical simulations performed in this study are designed to provide the information necessary for the broad analys is of a strontium-90 source located on a deep ocean floor. Although a specific set of conditions has been deemed to be a "representative" case, the model is also tested in response to possible sensitivities to certain perameters. Basically, the experiments can be divided into two categories: time simulation and parameter variation.

\section{TIME OF SIMULATION}

Oceanic studies of continuously releasing point sources often assume a steady rate of contaminant introduction (NUS 1975). This assumption permits the selection of a time period for the simulation which will allow a steady state concentration distribution to be approximated over a particular area of interest. However, a time-dependent source function, e.g., the source function used in this study, will not, in general, achieve a steady state. Consequently, four simulation periods are tested in this study: 10 days, 1 year, 2 years, and 5 years. The structure of the lateral concentration distributions of these four contaminant plumes are similar; Figures 1 and 2 are from the 10 day and 2 year simulation time experiments, respectively. Only onehalf of the contaminant plume is presented since the plume is symmetric with respect to the downstream centerline. The plume concentration distributions that are presented in Figures 1 and 2 exist in the same horizontal plane as the source.

For water in an unrestricted area the maximum permissible concentration (MPC) of ${ }^{90} \mathrm{Sr}$ is $3 \times 10^{-13} \mathrm{Ci} / \mathrm{cm}^{3}$ (Energy Regulations 1979). Comparing th is value with the ${ }^{90} \mathrm{Sr}$ concentration profiles in Figures 1 and 2 , one can define zones where the MPC criteria is exceeded. For example, the two year time simulation results in Figure 2 indicate that the ${ }^{90} \mathrm{Sr}$ concentration will exceed the MPC for a longitudinal distance of $3,000,000 \mathrm{~cm}(30 \mathrm{~km})$ from the source. 


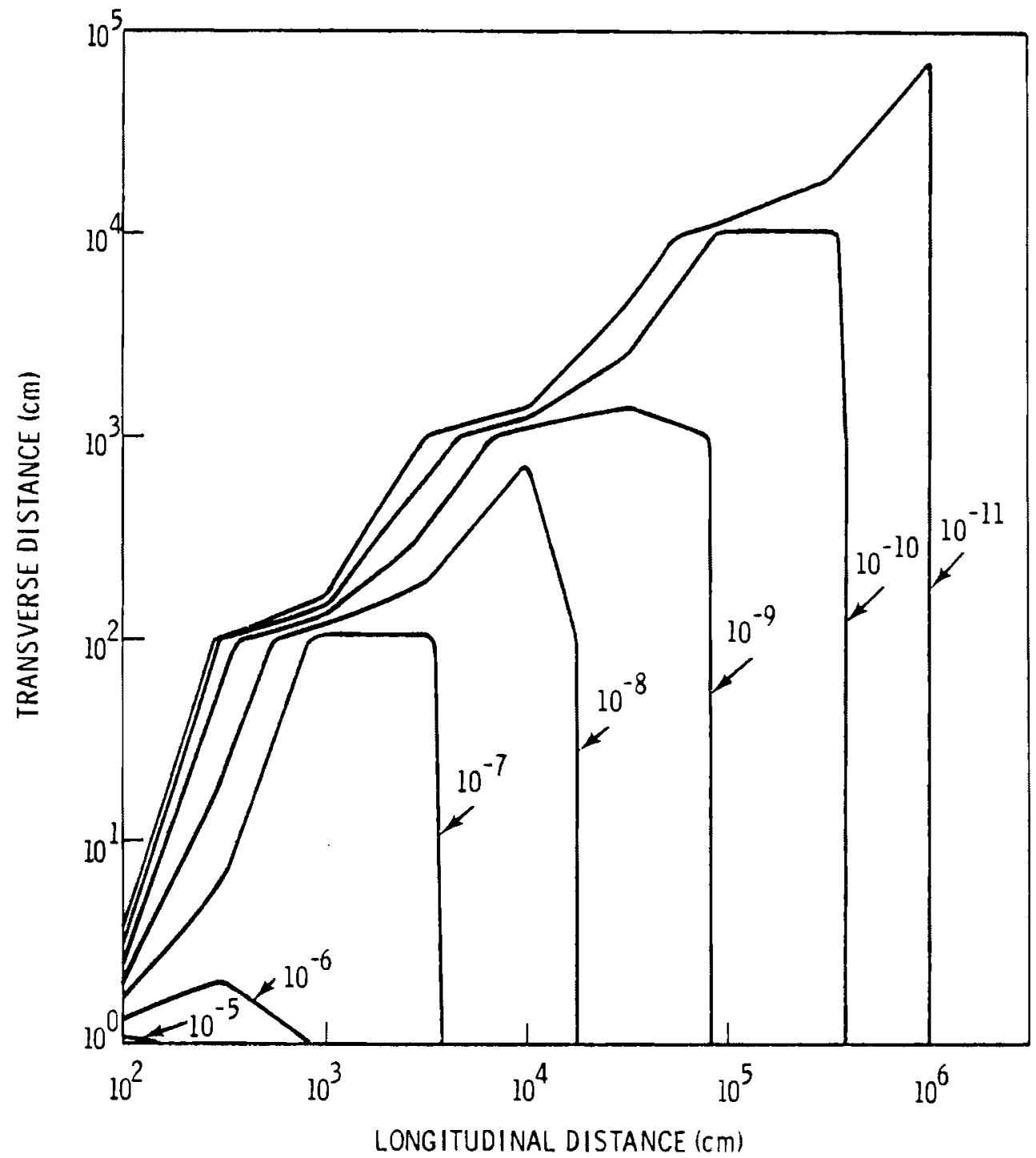

FIGURE 1. Horizontal Profile of Concentrations for 10 Days of Simulation $\left(\frac{\mathrm{Ci}}{\mathrm{cm}^{3}}\right)$

Figure 3 is a graph of the time simulation results when analyzed for concentration versus maximum distance from the source. For a given location in the contaminant plume, smaller time periods have larger concentrations. After one year of simulation, the MPC occurs at a longitudinal distance of $10,000,000 \mathrm{~cm}(100 \mathrm{~km})$ from the source. This is the largest distance from the source that this concentration will be found as the MPC contour recedes in subsequent time periods. Each study period exhibits a straightline portion of 


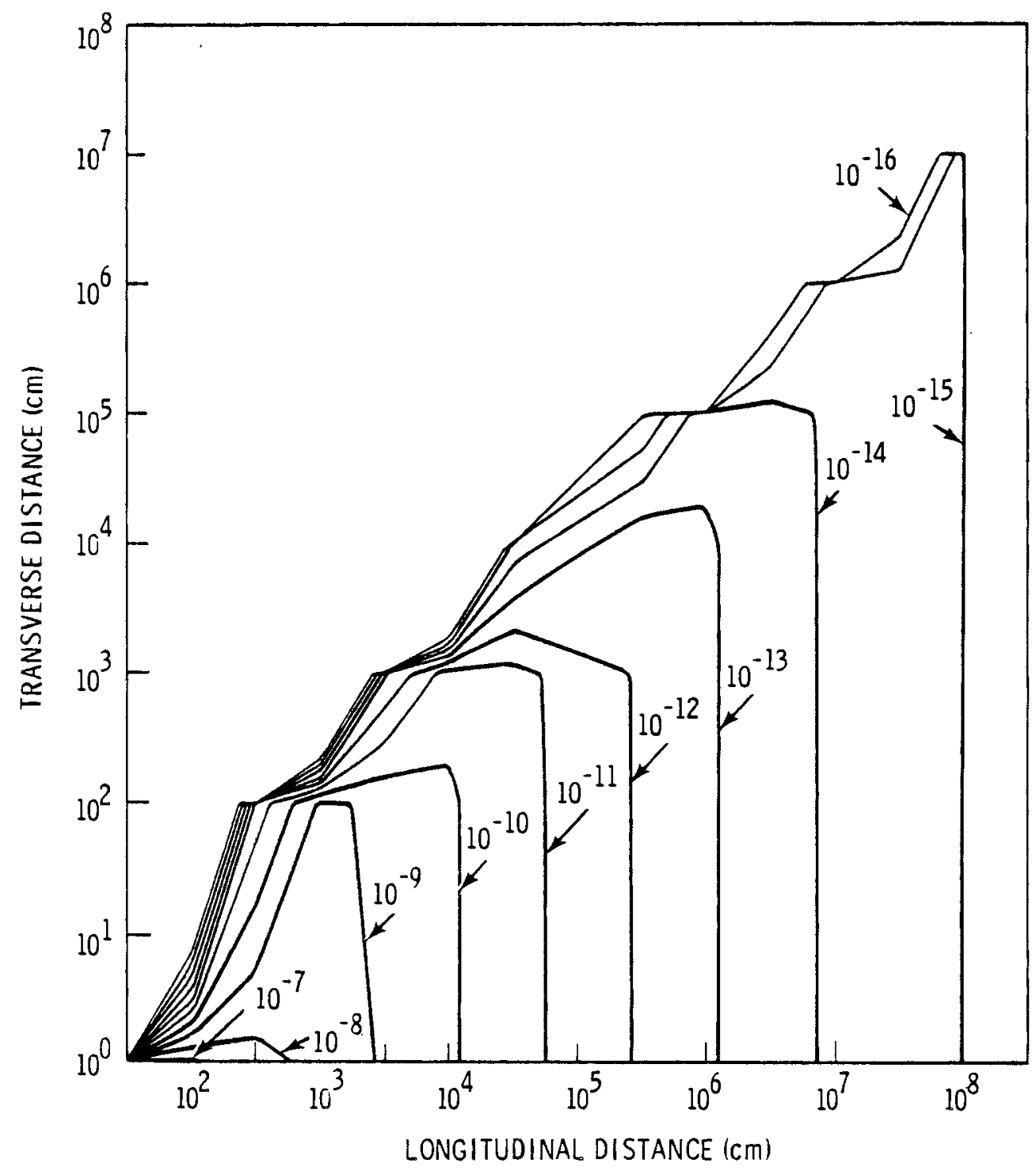

FIGURE 2. Horizontal Profile of Concentrations for 2 Years of Simulation $\left(\frac{C_{i}}{\mathrm{~cm}^{3}}\right)$

the curve near the source and a transient portion near the contaminant front; concentrations at the plume front drop off rapidly leaving a well-defined outer edge to the plume. In the straightline portion, all four slopes are identical. Whereas a transient behavior is not found in the 10 day period, a large variance from the linear behavior is obvious in the five year simulation near the convected plume front. The increase in concentration found at the front in the longer duration simulations is a result of the deterioration of 


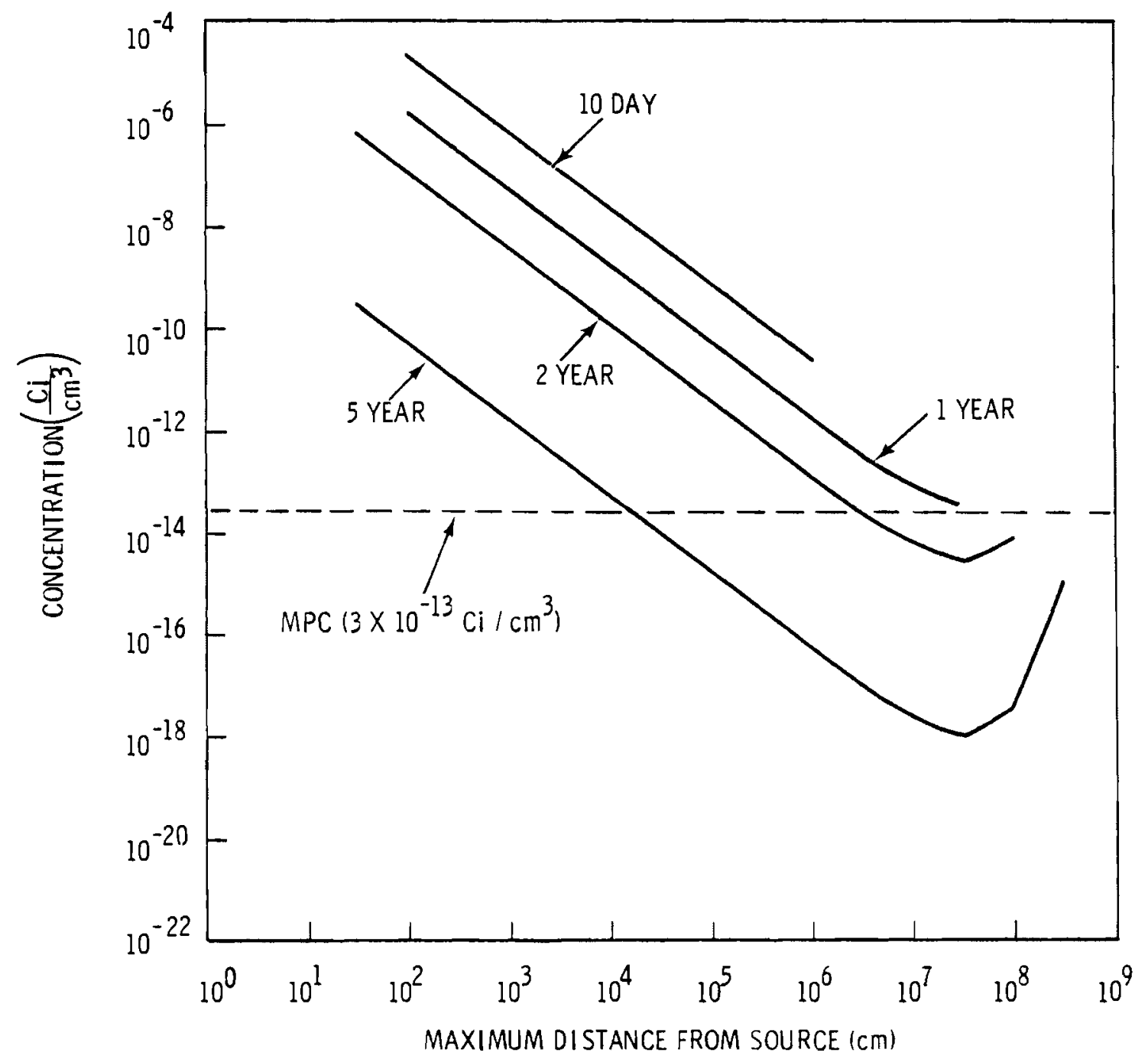

FIGURE 3. Concentration Versus Maximum Distance From Source: 10 Day, 1 Year, 2 Year, and 5 Year Time Periods

the original mass of strontium-90. After one year, the source function has been reduced by dissociation to $7 \%$ of the initial strength. Therefore, the front of the contaminant plume, which was influenced by the initial source strength, does not dilute as fast as the reduction caused by the decreasing source function.

The equation of the linear portion of these concentration versus maximum distance from the source curves is of the form: 


$$
S=K x^{-1.5}
$$

where the value of $K$ is 1 isted for each simulation period

\begin{tabular}{|c|c|}
\hline Simulation Period & $\mathrm{K}\left(\mathrm{Ci} \cdot \mathrm{cm}^{-1.5}\right)$ \\
\hline 10 day & $2.25 \times 10^{-2}$ \\
\hline 1 year & $1.77 \times 10^{-3}$ \\
\hline 2 year & $1.30 \times 10^{-4}$ \\
\hline 5 year & $5.16 \times 10^{-8}$ \\
\hline
\end{tabular}

Interpolation or regression techniques can be used to approximate other concentration-distance curves for different time periods provided the straightline assumption remains valid. For the conditions tested, the straight line approximation appears to be satisfactory up to a distance of $10^{5} \mathrm{~m}$.

\section{VARIATION OF PARAMETERS}

The effect of changing the magnitude of the source function is direct; doubling the strontium-90 mass available for dissociation will double the resulting concentrations. Thus, once a contaminant concentration distribution is generated, it is a simple matter to assess the effect of larger or smaller amounts of radioactive material.

In an earlier study, Toblin (1972) performed a sensitivity analys is upon the parameters of this model using the "spreading disc" approximation. The conclusions remain applicable for this study. It was shown that smaller values of $w, k_{z}, u$, and $z_{b}$ will all contribute to higher levels of contaminant. The mathematical simulation proposed in this instance is for a "worst possible case," i.e., the unlikely combination of parameters which will yield the highest concentration profiles. The parameters used are:

$$
\begin{aligned}
\omega & =0.2 \mathrm{~cm} / \mathrm{s} \\
k_{z} & =1.0 \mathrm{~cm}^{2} / \mathrm{s} \\
u & =0.0 \mathrm{~cm} / \mathrm{s} \\
z_{b} & =100 \mathrm{~cm}
\end{aligned}
$$


The simulation time for this test is one year. Figure 4 is a graph of the concentration versus maximum distance from the source. For the purpose of comparison, the standard one year simulation from the previous testing series is included in the figure. Caution must be exercised in the interpretation of these results because without velocity, the dispersion will proceed uniformly in all directions, whereas with a local current convecting the plume, mixing occurs primarily along the centerline of the plume. For a given concentration, it is possible to have more total activity near the source if the velocity is equal to zero than if the velocity is finite. This explains the lower concentrations found near the source for the extreme conditions tested. As in previous tests, the concentration-distance relation is log-linear near the source and nonlinear at the plume front. The flatter slope in the straightline portion of the graph differs from all other tests and is attributed to the absence of a convecting velocity. In this case, the transient portion of the graph is characterized by a gradual diminishing of contaminant concentration at large distances from the source. This phenomenon is due to the insufficient time provided for the cumulative effects of the continuously releasing source to occur. To a degree, this behavior is also observed in the finite velocity case although the decrease in concentration takes place over such a short distance that a well-defined front to the contaminant plume is created.

Each numerical simulation confirms the characteristic ineffectiveness of vertical mixing. Consider the case of the two year time simulation test. A vertical distribution of the plume concentrations is presented in Figure 5 . Concentrations comparable to those at the front are found at a transverse distance of 100,000 meters from the centerline axis of the plume (see Figure 2), while similar concentrations are detected only 100 meters vertically from the axis.

Throughout both testing series, the solubility of the dissolved strontium-90 was monitored to ensure that the condition of immediate dissolution assumed in the model was reasonable. In fact, no concentration in this study significantly exceeded the background level of strontium in seawater. 


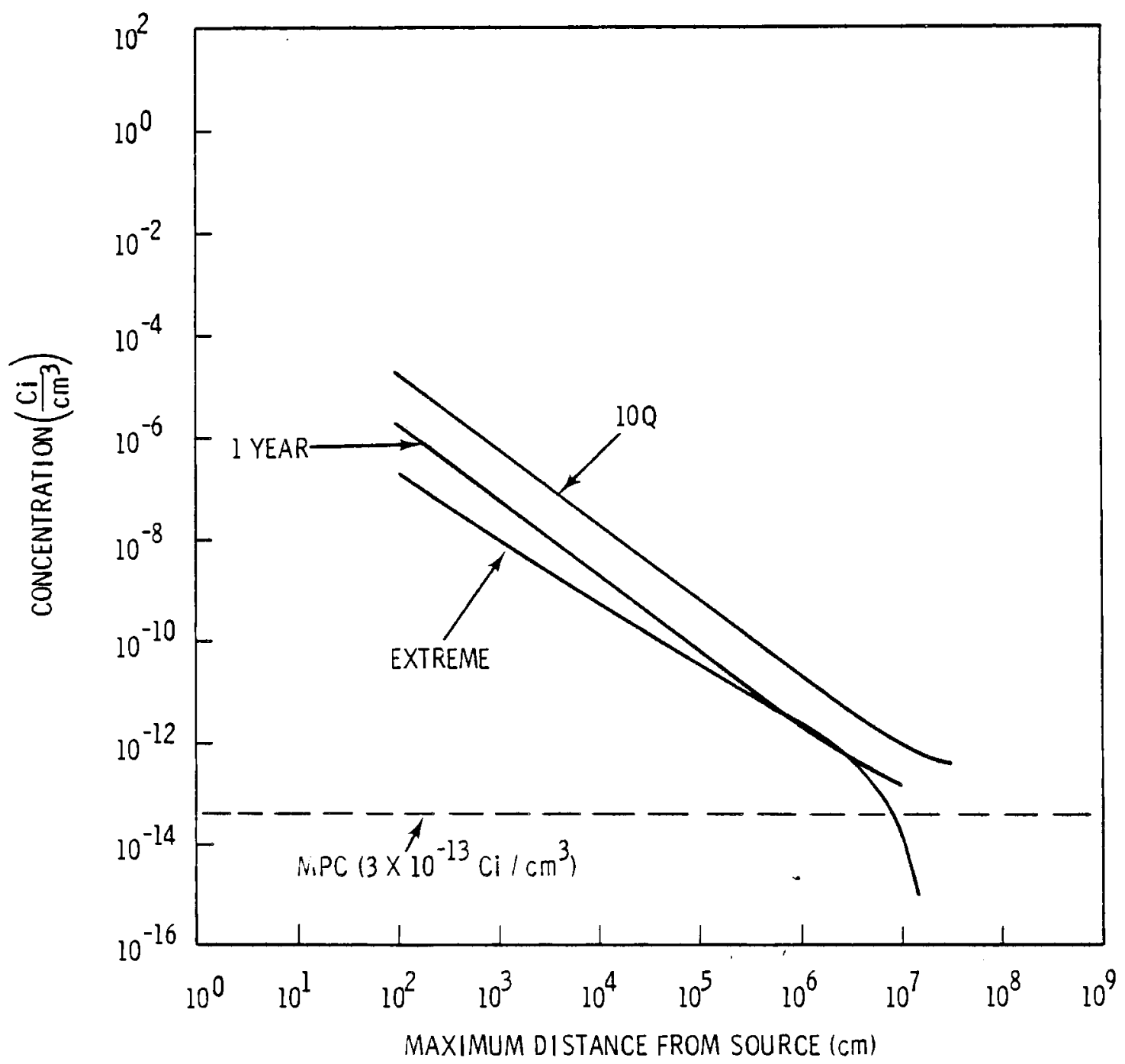

FIGURE 4. Concentration Versus Maximum Distance From Source: Increased Source (10Q), Extreme Conditions, and 1 Year Baseline 


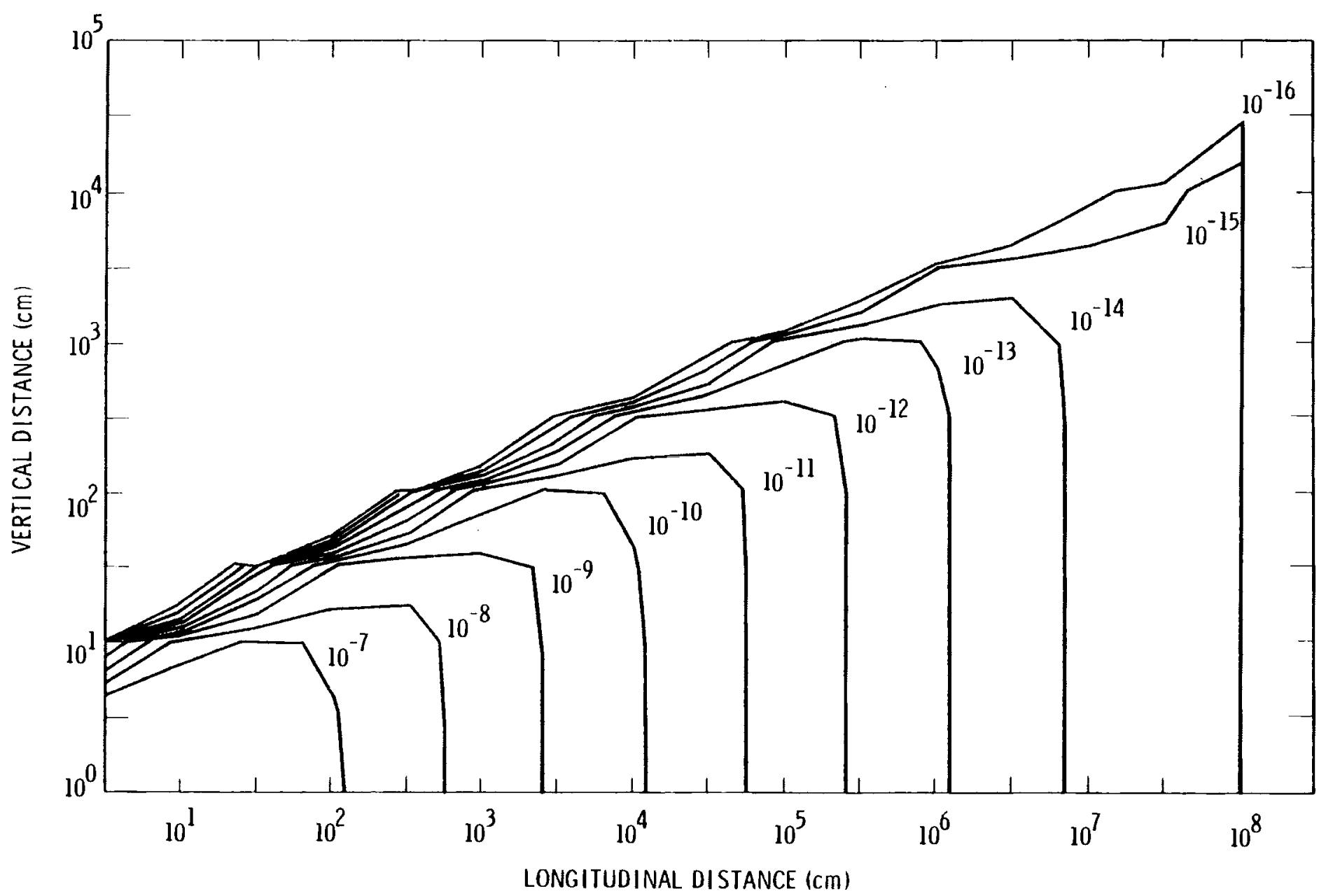

FIGURE 5. Vertical Profile of Concentrations for 2 Years of Simulation $\left(\frac{\mathrm{Ci}}{\mathrm{cm}^{3}}\right)$ 
VI. CONCLUSIONS

A modified version of the Okubo-Pritchard diffusion velocity dispersion model has been applied to a time dependent continuous fixed source of strontium-90 on the deep ocean floor. The model features three-dimensional mixing by means of a radially symmetrical treatment of the horizontal diffusion process and a constant diffusivity to approximate the vertical diffusion parameter. Data input into the model is designed to simulate the release of contaminant from a nonspecific location in the deep ocean layer.

Plots of the horizontal distribution of concentrations are presented for two cases. Mathematical relationships for four time periods have been identified to allow the computation of concentrations without applying the model. In an effort to bracket the range of concentrations possible, an extreme set of conditions was also tested.

Results of the numerical testing program indicate that the deep ocean is capable of diluting and containing the release of the strontium-90 radionuclide. This is due, in part, to the anisotropic nature of the dispersion mechanism in the ocean. Vertical mixing is not effective and as a resuit, released solutes are confined to a layer at the level of introduction. The mean residence time of this layer is such that radioactive decay becomes significant in reducing the activity of the contaminant plume. In the horizontal plane, ambient currents and/or large-scale eddy motions comb ine with turbulent diffusion to produce a relatively strong mixing and dilution of the contaminant. For the amount of strontium-90 considered to be in the source, the absolute concentrations in all simulations were found to be not significantly higher than the existing natural levels of strontium found in seawater.

With respect to water quality, the applicable standard is the maximum permissible concentration (MPC) of strontium-90 in water in an unrestricted area. Modeling results show that, in the horizontal plane, the MPC is exceeded for considerable downstream distances from the point of release, with the maximum affected volume occurring after one year of simulation. Vertical radionuclide migration is limited to a minute fraction of the iongitudinal effect. 
The scenario used in this study assumes that the entire mass of ${ }^{90} \mathrm{SrF}_{2}$ in the heat source capsule is instantaneous iy exposed to seawater. In an actual occurrence, it is unlikely that a capsule would release all of its contents at once; most probably the exposure of ${ }^{90} \mathrm{Sr}_{2}$ would be restricted to some finite rate. Therefore, the results of this study inherently contain a degree of conservatism. 


\section{REFERENCES}

Energy Regulations, 10 C.F.R. Part 20. 1979.

Fullam, H. T. 1976. The Solubility and Dissolution Behavior of $90 \mathrm{SrF}$ ? in Aqueous Media. BNWL-2101, Pacific Northwest Laboratory, Richland, Washington.

Fullam, H. T. 1977. Strontium-90 Fluoride Data Sheet. BNWL-2284, Pacific Northwest Laboratory, Richland, Washington.

NUS Corporation. 1975. Technical Models. Volume 2 of Overall Safety Manual. Environmental Systems Group, Rockville, Maryland.

Okubo, A., and D. W. Pritchard. 1969. Summary of Our Present Knowledge of the Physical Processes of Mixing in the Ocean and Coastal Waters, and a Set of Practical Guidelines for the Application of Existing Diffusion Equations in the Preparation of Nuc lear Safety Evaluations of the Use of Nuc lear Power Sources in the Sea. NY0-3109-40, Chesapeake Bay Institute, Baltimore Maryland.

Okubo, A. 1962. Horizontal Diffusion from an Instantaneous Point-Source Due to Oceanic Turbu lence. NY0-8104, Chesapeake Bay Institute Report, Baltimore, Maryland.

Pritchard, D. W. 1960. "The Application of Existing Oceanographic Knowledge to the Problem of Radioactive Waste Disposal into the Sea." Disposal of Radioactive Wastes II, pp. 229-253, International Atomic Energy Agency, Vienna.

Toblin, A. 1972. Aquatic Diffusion Analys is for Plutonium Fueled Space Nuclear System. SNS-NUS-933, NUS Corporation--Environmental Safeguards Division, Rockville, Maryland. 



\section{DISTRIBUTION}

No. of

Copies

OFFSITE

A. A. Churm

DOE Patent Division

9800 S. Cass Avenue

Argonne, IL 60439

F. E. Coffman

DOE Office of Advanced Nuclear Systems and Projects, NE-540 Washington, DC 20545

G. L. Bennett

DOE Space and Terrestrial

Systems Division, NE-543

Washington, DC 20545

B. J. Rock

DOE Space and Terrestrial

Systems Division, NE-543

Washington, DC 20545

J. J. Lombardo

DOE Space and Terrestrial

Systems Division, NE-543

Washington, DC 20545

25 W. C. Remini

DOE Space and Terrestrial

Systems Division, NE-543

Washington, DC 20545

W. Savage

DOE Space and Terrestrial

Systems Division, NE-543

Washington, DC 20545

J. M. Maddox

DOE

E201

Washington, DC 20545

C. A. Cooley

DOE Waste Management Division

Washington, DC 20545
No. of

Copies

G. Dertel

DOE Waste Management Division

Washington, DC 20545

D. C. Davis, Jr.

DOE Oak Ridge Operations Office

P.0. Box E

Oak Ridge, TN 37830

W. T. Goldston

DOE Savannah River Operations Office

P.0. Box A

Aiken, SC 29801

27 DOE Technical Information Center

L. L. Jardine

Argonne National Laboratory

9700 South Cass Avenue

Argonne, IL 60439

R. T. Huntoon

E. I. duPont deNemours and Company

Savannah River Laboratory

Aiken, SC 29801

S. E. Bronisz

Los Alamos Scientific Laboratory

P.0. Box 1663

Los Alamos, MN 87544

J. S. Sivinski

Division 4535

Sandia Laboratories

Albuquerque, NM 87185

W. T. Cave

Monsanto Research Corporation

Mound Laboratory (DOE)

Nuclear Operations

P.0. Box 32

Miamisburg, $\mathrm{OH} 45342$ 
No. of

Copies

Department of the Army

Headquarters, U.S. Army

Facilities Enegineering Support Agency

Fort Belvoir, VA 22060

H. H. Musselman, Tech. Dir.

Officer in Charge

J. H. Vogt

Naval Nuclear Power Unit

Code 70

Port Hueneme, CA 93043

H. V. Weiss

Code 631

Naval Ocean Systems Center

San Diego, CA 92152

2 A. A. Arcuni

Naval Facilities Engineering Command

Office of Special Assistant Nuclear Programs (O4N)

200 Stovall Street

Alexandria, VA 22332

K. W. Haff

Oak Ridge National Laboratory

Oak Ridge, TN 37830

J. Hammond

Oak Ridge National Laboratory

Oak Ridge, TN 37830

J. R. Keiser

Oak Ridge National Laboratory

Oak Ridge, TN 37830

3 E. Lamb

Oak Ridge National Laboratory

Oak Ridge, TN 37830

2 B. J. Tharpe

General Electric Company

Space Division

P.0. Box 8661

Philadelphia, PA 19101
No. of

Copies

2 R. Englehart

NUS Corporation

4 Research Place

Rockville, MD 20850

2 P. Dick

Teledyne Energy Systems

110 W. Timonium Road

Timonium, MD 21093

C. C. Silverstein

Westinghouse Astronuclear

Laboratory

P.0. Box 10864

Pittsburgh, PA 15236

Battelle Memorial Institute

Office of Nuclear Waste Isolation

Attn: Beverly Rawles

505 King Avenue

Columbus, Ohio 43201

$\underline{\text { ONSITE }}$

3 DOE Richland Operations

D. Bogon

R. E. Gerton

H. E. Ransom

8 Rockwell Hanford Operations

L. I. Brecke

H. H. Hopk ins

J. D. Kaser

E. J. Kosiancic

T. H. May

D. Ramey

J. P. Sloughter

C. R. Stroup

31 Pacific Northwest Laboratory

H. T. Fullam (20)

R. E. Night ingale

L. D. Perrigo

H. H. Van Tuyl

S. Yabusaki

Technical Files (5)

Publishing Coordination $B E(2)$ 
